\title{
Epicondylitis among cooks in nursery schools
}

Yuichiro Ono, Ryogo Nakamura, Midori Shimaoka, Shuichi Hiruta, Yoji Hattori, Gaku Ichihara, Michihiro Kamijima, Yasuhiro Takeuchi

Fujita Health

University School of

Medicine, Department

of Public Health, 1-98

Dengakugakubo,

Kutsukake-cho,

Toyoake,

Aichi-prefecture

470-11, Japan

Y Ono

Nagoya University School of Medicine, Department of

Orthopaedic Surgery, 65 Tsurumai-cho,

Showa-ku, Nagoya 466,

Japan

R Nakamura

Nagoya University, Research Centre of Health, Physical Fitness, and Sports, Furo-cho, Chikusa-ku,

Nagoya 464, Japan

M Shimaoka

$S$ Hiruta

Daido Institute of Technology,

Department of

Physical Education,

10-3 Takiharu-cho,

Minami-ku, Nagoya

457, Japan

Y Hattori

Nagoya University

School of Medicine,

Department of

Hygiene, 65

Tsurumai-cho,

Showa-ku, Nagoya 466,

Japan

G Ichihara

M Kamijima

Y Takeuchi

University of

California,

Environmental

Chemistry and

Toxicology Laboratory,

Department of

Environmental

Science, Policy and

Management,

Berkeley, CA USA

M Kamijima

Correspondence to:

Dr Y Ono, Department of

Public Health, Fujita Health

University School of

Medicine, 1-98

Dengakugakubo,

Kutsukake-cho, Toyoake,

Aichi-prefecture 470-11,

Japan. Tel: 008156293

2452 or 2453; Fax: 0081562

933079 .

Accepted 31 October 1997

\begin{abstract}
Objectives-To investigate the prevalence and risk factors of epicondylitis among cooks in nursery schools in a cross sectional study because they are suspected to have strenuous workloads on the hands and arms.
\end{abstract}

Methods-Prevalence of epicondylitis among 209 nursery school cooks and 366 control workers aged 40-59 were studied. Both groups consisted of women workers chosen from 1299 subjects who agreed to participate from 1329 social welfare employees in a city. All workers were interviewed with a questionnaire and had a clinical examination of the tenderness to palpation of epicondyles and epicondylar pain provoked by resisted extension and flexion of the wrist.

Results-Nursery school cooks had a significantly higher prevalence of epicondylitis $(11.5 \%)$ than the controls (2.5\%). In a logistic regression model, job title of the cook was also found to have a strong association with epicondylitis (odds ratio (OR) 5.4, 95\% confidence interval (95\% CI) 2.4 to 11.9 ) after adjustment for age, body length, and body mass index. Weaker associations were also found between epicondylitis and suspected job stress or workload scores for mechanical workload and psychosocial stressors based on factor analysis.

Conclusions-This study supported the hypothesis that nursery school cooks had a higher prevalence of epicondylitis than other workers with less strenuous hand and arm tasks. It was suggested that risk factors of epicondylitis would be multifactorial, including mechanical workload and psychosocial factors.

(Occup Environ Med 1998;55:172-179)

Keywords: epicondylitis; cooks; cross sectional

There have been several studies reporting a higher prevalence of musculoskeletal problems in cooks than in other occupational workers. ${ }^{1-4}$ Ergonomic factors including working height, lifting load, and the number of lunches prepared were found to be risk factors as well as individual capacity of workers including age and body length..$^{5-8}$ Shibata et al found that inadequate working conditions - such as difficulty in taking rest - could also be a risk factor for musculoskeletal disorders in cooks. ${ }^{8}$ Some of these epidemiological studies, however, were not free from potential bias because they had high non-response rates. Also, there are few epidemiological studies on cooks in small workplaces like nursery schools, even though they repeat tasks considered to use arms and hands forcefully. ${ }^{9}$ Winkel and Mathiassen proposed three main dimensions of mechanical work exposure: level, repetitiveness, and duration. ${ }^{10}$ Repetitive work has been defined as physical work tasks with similar work cycles and repetitiveness performed repeatedly. ${ }^{11}$ In the development of cumulative trauma disorders, jobs with the combination of high force and high repetitiveness were found to involve high risks. ${ }^{12}$ Similarly, highly repetitive and forceful work was considered to be a risk for elbow disorders as it strains the muscle-tendon structures of the arms. ${ }^{13-15}$ Thus, it was considered that the prevalence of epicondylitis would be higher in nursery school cooks, due to their frequent repetitive and forceful hand and arm tasks, than in other workers with less strenuous tasks. The aim of this cross sectional study was to investigate the prevalence and risk factors of epicondylitis in nursery school cooks.

\section{Methods}

SUBJECTS

The public welfare department of a city in Aichi Prefecture in Japan and its labour union agreed to participate in a health check and study project dealing with musculoskeletal problems among social welfare workers. A questionnaire was distributed to all social welfare employees in the city except for nursery school teachers and clerical workers. Of these 1329 subjects, 1299 (97.7\%) agreed to participate in the project. To ensure homogeneity of sex and working conditions of the subjects for analyses, 101 female cooks not employed at nursery schools and 316 male workers were excluded. The remaining 882 female workers consisted of 230 nursery school cooks and 652 workers performing other jobs. In this study, subjects aged 40-59 were chosen because of the few cooks in other age ranges. Finally, 209 nursery school cooks (cooks) and 366 control workers in other occupations (controls) comprised the study population. The controls consisted of nursing assistants $(n=135)$, nurses for the aged $(n=95)$, home care service workers $(n=82)$, nursery workers for the handicapped $(n=38)$, and handywomen $(n=16)$. The mean (SD) age was 49.6 (4.6) for the cooks and 48.3 (5.8) for the controls. The cooks had been working for 14.1 (5.1) years at the time and the controls for 13.4 (6.6) years.

\section{JOB DESCRIPTION}

In visits to the workplaces, the occupation of cook was classified as having tasks with forceful and highly repetitive hand and arm movements while cooking, dish washing, and cleaning of 
Table 1 List of variables for the analysis

Questionnaire:
Age
Sex
Duration of employment in the present jobs
Dominant hand
Habit of playing tennis and other ball games
Job title
Self estimated job stressors and workload
Number of meals to be prepared (for cooks only)
Number of cooks making lunch meals (for cooks only)
Clinical examination:
Body length
Body weight
Finding in palpation of epicondyles
Findings in resisted extension and flexion of the wrist
Grip strength

the workplaces. The controls were regarded as having tasks that involved bending the trunk and occasionally forceful but not highly repetitive hand and arm movements compared with the cooks.

\section{QUESTIONNAIRE}

A questionnaire was developed to assess workload, job stressors, and personal data of the subjects. It contained demographic variables such as age, duration of employment in the present job, and the dominant hand (table 1). The questionnaire asked about self estimated job stressors and workload as well as the habit of playing tennis and other ball games. The cooks were also asked about the numbers of cooks they worked with and the numbers of meals to be prepared (table 1). Arm pain was listed in the questionnaire but was not analysed in the study because the pain was not specific to the elbow region. The questionnaires were given to the subjects by their supervisors in the workplaces with the request to complete them before an interview. They were interviewed on the same day as the clinical examination, and only answers regarded as being based on apparent misunderstanding were corrected.

\section{CLINICAL EXAMINATION}

Clinical examination was carried out in December 1990. The epicondyle was examined for tenderness to palpation of the lateral and medial epicondyles and epicondylar pain pro-

Table 2 Factor pattern of self estimated job stressors and workload calculated by factor analysis with varimax rotation $(n=575)$

\begin{tabular}{llll}
\hline & \multicolumn{2}{l}{ Factor loading } \\
\cline { 2 - 4 } & Factor 1 & Factor 2 & Factor 3 \\
\hline Frequent lifting and handling of objects & 0.155 & $0.569^{\star}$ & 0.233 \\
Static work posture & 0.158 & $0.786^{\star}$ & 0.031 \\
Frequent repetitive work with shoulders, arms, hands, or & & & \\
$\quad$ fingers & 0.077 & $0.806^{\star}$ & 0.033 \\
Too much work & 0.090 & $0.576^{\star}$ & $0.563^{\star}$ \\
Too many different tasks & 0.111 & $0.510^{\star}$ & $0.532^{\star}$ \\
Too much responsibility & 0.204 & 0.059 & $0.747^{\star}$ \\
Much concentration required & 0.306 & 0.016 & $0.610^{\star}$ \\
Great time pressures & 0.008 & 0.474 & $0.591^{\star}$ \\
Shortage of staff & 0.252 & 0.316 & $0.498^{\star}$ \\
Difficult human relations at work & $0.573^{\star}$ & 0.001 & 0.298 \\
Inexperienced in handling tasks & $0.566^{\star}$ & 0.047 & 0.199 \\
Much unplanned work & $0.491^{\star}$ & 0.148 & 0.347 \\
Extra work due to poor physical condition of colleagues & $0.565^{\star}$ & 0.250 & 0.192 \\
Role ambiguity in the workplace & $0.724^{\star}$ & 0.115 & 0.060 \\
Difficulties in realising one's ideas & $0.701^{\star}$ & 0.055 & 0.149 \\
Lack of frank discussion about work problems & $0.727^{\star}$ & 0.189 & -0.056 \\
Difficulties in lowering workload at reduced working & & & \\
$\quad$ capacity & 0.191 & $0.497^{\star}$ & 0.423 \\
\hline
\end{tabular}

^Items mainly constituting the factor are marked. voked by resisted extension and flexion of the wrist with the elbow extended. An occupational physician conducted the examinations. The examiner had no knowledge of the occupation of the subjects at the time. Tenderness was checked first at the lateral humeral epicondyle, $1-2 \mathrm{~cm}$ distal to it, and in the anterior area over the common extensor tendons. Tenderness was also checked at the medial humeral epicondyle, 1-2 cm distal to it and the area slightly anterior. The severity of the tenderness was assessed by the oral and behavioural response of the subject to the manual pressure as follows: $0=$ evoking little or no pain; $1=$ evoking moderate pain without escaping reaction from the pressed site; $2=$ evoking severe pain or an escaping reaction due to pain; and $3=$ evoking pronounced irresistible pain with considerable escaping reaction. In the resisted wrist extension and flexion tests, findings were ranked as follows: $0=$ provoking little or no pain at the epicondyle region without any decrease in the wrist movement of the subject; $1=$ provoking moderate pain at the epicondyle region with slight decrease in wrist movement; $2=$ provoking severe pain at the epicondyle region with decrease in wrist movement due to elbow pain; and $3=$ provoking pronounced irresistible pain at the epicondyle region accompanied by difficulty in wrist movement or abrupt stopping of the movement. In the analyses, palpation and the resisted wrist extension and flexion tests were dichotomised into positive $(\geqslant 2)$ and almost negative ( 0 or 1$)$, as 2 and 3 were defined as epicondylitis severe enough to interfere with work. Lateral epicondylitis was defined as the condition with positive findings both in the examination for tenderness to palpation at the lateral epicondyle and in the resisted wrist extension test. Medial epicondylitis was similarly defined as that with both positive findings in the examination for the tenderness at the medial epicondyle and in the resisted flexion test. Isometric strength of grip was measured with a dynamometer (grip strength meter: Takei-kiki Kogyo). Body length and body weight were also measured. Body mass index (BMI) was calculated later as a body measurement not highly correlated with body length. Six days in total were needed to examine the subjects.

\section{STATISTICAL ANALYSES}

The prevalence of the clinical findings of the cooks and controls were compared by calculating prevalence odds ratio (OR) and its 95\% confidence interval (95\% CI). ${ }^{16}$ When the number of the subjects with a positive finding was zero in a cell, the logit estimator for the OR was calculated by adding 0.5 to the cell. ${ }^{17}$ The proportion (\%) of workers with the self estimated job stressors and workload were compared between cooks and controls by calculating OR and 95\% CI. Seventeen self estimated job stressors and workload were also grouped into several main factor groups according to the factor loading calculated by factor analysis. The number of complaints of job stressors and workload in each main factor group was counted as a suspected job stressor 
Table 3 Findings in clinical check up of the epicondyles among cooks in nursery schools and controls (examinations were carried out of tenderness to palpation of epicondyles and epicondylar pain provoked by resisted extension and flexion of the wrist)

\begin{tabular}{|c|c|c|c|c|}
\hline Examination & Arm & Scores * & $\begin{array}{l}\text { Cooks }(n=209) \\
n(\%)\end{array}$ & $\begin{array}{l}\text { Controls }(n=366) \\
n(\%)\end{array}$ \\
\hline \multirow[t]{8}{*}{ Palpation of lateral epicondyle } & \multirow[t]{4}{*}{ Right } & 0 & $119(56.9)$ & $292(79.8)$ \\
\hline & & 1 & $50(23.9)$ & 49 (13.4) \\
\hline & & 2 & $37(17.7)$ & $24(6.6)$ \\
\hline & & 3 & $3(1.4)$ & $1(0.3)$ \\
\hline & \multirow[t]{4}{*}{ Left } & 0 & $158(75.6)$ & $336(91.8)$ \\
\hline & & 1 & $33(15.8)$ & $18(4.9)$ \\
\hline & & 2 & $17(8.1)$ & $11(3.0)$ \\
\hline & & 3 & $1(0.5)$ & $1(0.3)$ \\
\hline \multirow[t]{8}{*}{ Palpation of medial epicondyle } & \multirow[t]{4}{*}{ Right } & 0 & $177(84.7)$ & $354(96.7)$ \\
\hline & & 1 & $14(6.7)$ & $9(2.5)$ \\
\hline & & 2 & $18(8.6)$ & $3(0.8)$ \\
\hline & & 3 & $0(0.0)$ & $0(0.0)$ \\
\hline & \multirow[t]{4}{*}{ Left } & 0 & $182(87.1)$ & $351(95.9)$ \\
\hline & & 1 & $12(5.7)$ & $5(1.4)$ \\
\hline & & 2 & $15(7.2)$ & $10(2.7)$ \\
\hline & & 3 & $0(0.0)$ & $0(0.0)$ \\
\hline \multirow[t]{8}{*}{ Resisted wrist extension } & \multirow[t]{4}{*}{ Right } & 0 & $187(89.5)$ & $359(98.1)$ \\
\hline & & 1 & $6(2.9)$ & $0(0.0)$ \\
\hline & & 2 & $15(7.2)$ & $6(1.6)$ \\
\hline & & 3 & $1(0.5)$ & $1(0.3)$ \\
\hline & \multirow[t]{4}{*}{ Left } & 0 & $192(91.9)$ & $361(98.6)$ \\
\hline & & 1 & $5(2.4)$ & $1(0.3)$ \\
\hline & & 2 & $10(4.8)$ & $3(0.8)$ \\
\hline & & 3 & $2(1.0)$ & $1(0.3)$ \\
\hline \multirow[t]{8}{*}{ Resisted wrist flexion } & \multirow[t]{4}{*}{ Right } & 0 & $205(98.1)$ & $366(100.0)$ \\
\hline & & 1 & $3(1.4)$ & $0(0.0)$ \\
\hline & & 2 & $1(0.5)$ & $0(0.0)$ \\
\hline & & 3 & $0(0.0)$ & $0(0.0)$ \\
\hline & \multirow[t]{4}{*}{ Left } & 0 & $204(97.6)$ & $366(100.0)$ \\
\hline & & 1 & $2(1.0)$ & $0(0.0)$ \\
\hline & & 2 & $3(1.4)$ & $0(0.0)$ \\
\hline & & 3 & $0(0.0)$ & $0(0.0)$ \\
\hline
\end{tabular}

${ }^{\star}$ Scores of palpation of epicondyles: $0=$ evoking little or no pain, $1=$ evoking moderate pain without escaping reaction, $2=$ evoking severe pain or escaping reaction due to pain, and $3=$ evoking pronounced irresistible pain with marked escaping reaction.

Scores of resisted wrist extension or flexion: $0=$ provoking little or no pain at the epicondyle region without any decrease in the wrist movement, 1 =provoking moderate pain at the epicondyle region with slight decrease in wrist movement, $2=$ provoking severe pain at the epicondyle region with decrease in wrist movement due to elbow pain, 3 =provoking pronounced irresistible pain at the epicondyle region accompanied by difficulty in movement or abrupt stop of wrist movement.

or workload score. In factor analyses, varimax rotation was used to obtain the final factor pattern. Logistic regression techniques were used to examine explanatory models for epicondylitis by adjusting for several possible confounding factors simultaneously. Likelihood ratio (LR) $\chi^{2}$ tests were used in the process of selection and elimination of variables including interactions between exposure and possible confounding variables in the logistic models. ${ }^{18}$ The Spearman rank correlation coefficient was also calculated between variables to avoid multicollinearity of independent variables in logistic models. In this study, significance was indicated when the lower limit of the $95 \%$ CI of an OR was $>1.0$ as well as when the upper limit of
$95 \%$ CI was $<1.0$. Statistical analyses were carried out with SAS software (SAS Institute) on the main frame in the Computer Centre of Nagoya University (M-1800/20, Fujitsu). ${ }^{19}$

The self estimated job stressors and workload were grouped into three main factors after varimax rotation by factor analysis (table 2). The first factor (factor 1) consisted of seven items of psychosocial stressors suggesting difficult human relations, role ambiguity, and poor work organisation. Factor 2 consisted of six items related to high mechanical workload. Factor 3 was the factor constructed by six items suggesting too much work. Two items of too much work and too many different tasks were included in both factors 2 and 3 because they gave similar factor loadings in both factors. Then, the number of complaints of self estimated job stressors and workload that formed each factor were counted, and were called job stressor (JS) or workload scores: JS1 for factor 1, JS2 for factor 2, and JS3 for factor 3. Thus JS1 was used as a suspected summary score for psychosocial stressors, JS2 for mechanical workload, and JS3 for the amount of work.

\section{Results}

COMPARISON BETWEEN THE COOKS AND

CONTROLS

Results of palpation of the lateral and medial epicondyles were more severe in cooks than in controls (table 3 ). In resisted wrist extension and flexion tests, results also tended to be more severe in cooks than in controls (table 3 ).

The cooks had a higher prevalence of positive findings than the controls, and all the ORs exceeded 1.0 as did the lower limits of the $95 \%$ CIs except for that of the resisted wrist flexion test (table 4). Lateral and medial epicondylitis $(O R \geqslant 4.0)$ were more prevalent among cooks than controls (table 5). However, the $95 \%$ CIs for medial epicondylitis were large and the lower limit was $<1.0$. The predominance of epicondylitis of the lateral over the medial site was found in both groups of workers (cooks OR 8.1, 95\% CI 2.4 to 27.4; controls OR $18.4,95 \%$ CI 1.1 to 319.1 ). Lateral epicondylitis tended to be slightly more prevalent in the right arm than in the left arm among both types of workers (cooks OR 1.8, $95 \%$ CI 0.8 to 4.3 ; controls OR $1.8,95 \%$ CI

Table 4 Prevalence of pain on palpation at the epicondyles and resisted wrist extension or flexion test with OR (95\% CI) in nursery school cooks and controls

\begin{tabular}{|c|c|c|c|c|}
\hline Findings & Arm & $\begin{array}{l}\text { Cooks } \\
(n=209) \\
n(\%)\end{array}$ & $\begin{array}{l}\text { Controls } \\
(n=366) \\
n(\%)\end{array}$ & $O R^{\star}(95 \% C I)$ \\
\hline \multicolumn{5}{|l|}{ Positive findings at lateral epicondyle: } \\
\hline \multirow[t]{3}{*}{ Tenderness in palpation } & Right & $40(19.1)$ & $25(6.8)$ & $2.8(1.9$ to 5.5$)$ \\
\hline & Left & $18(8.6)$ & $12(3.3)$ & $2.7(1.3$ to 5.9$)$ \\
\hline & Right or left & $42(20.1)$ & $28(7.7)$ & $2.6(1.8$ to 5.1$)$ \\
\hline \multirow[t]{3}{*}{ Positive sign in resisted wrist extension test } & Right & $16(7.7)$ & $7(1.9)$ & $4.1(1.7$ to 10.5$)$ \\
\hline & Left & $12(5.7)$ & $4(1.1)$ & $5.4(1.8$ to 17.3$)$ \\
\hline & Right or left & $23(11.0)$ & $9(2.5)$ & $4.5(2.2$ to 10.8$)$ \\
\hline \multicolumn{5}{|l|}{ Positive findings at medial epicondyle: } \\
\hline \multirow[t]{3}{*}{ Tenderness in palpation } & Right & $18(8.6)$ & $3(0.8)$ & 9.9 (3.3 to 39.2$)$ \\
\hline & Left & $15(7.2)$ & $10(2.7)$ & $2.5(1.2$ to 6.2$)$ \\
\hline & Right or left & $24(11.5)$ & $11(3.0)$ & $3.7(2.0$ to 8.7$)$ \\
\hline \multirow[t]{3}{*}{ Positive sign in resisted wrist flexion test } & Right & $1(0.5)$ & $0(0.0)$ & $5.3(0.2$ to 130$)$ \\
\hline & Left & $3(1.4)$ & $0(0.0)$ & $12.4(0.6$ to 242$)$ \\
\hline & Right or left & $4(1.9)$ & $0(0.0)$ & $16.1(0.9$ to 300$)$ \\
\hline
\end{tabular}

*When the number of subjects with pain was zero, the logit estimator for OR was calculated by adding 0.5 . 
Table 5 Prevalence of epicondylitis with prevalence OR $(95 \%$ CI) in nursery school cooks and controls

\begin{tabular}{llclc}
\hline Diagnosis & Arm & $\begin{array}{l}\text { Cooks } \\
(n=209) \\
n(\%)\end{array}$ & $\begin{array}{l}\text { Controls } \\
(n=366) \\
n(\%)\end{array}$ & OR* $(95 \%$ CI) \\
\hline Lateral epicondylitis & Right & $16(7.7)$ & $7(1.9)$ & $4.3(1.8$ to 9.8$)$ \\
& Left & $9(4.3)$ & $4(1.1)$ & $4.0(1.3$ to 12.3$)$ \\
Medial epicondylitis & Right or left & $22(10.5)$ & $9(2.5)$ & $4.7(2.2$ to 9.7$)$ \\
& Right & $1(0.5)$ & $0(0.0)$ & $5.3(0.2$ to 130$)$ \\
Epicondylitist & Left & $2(1.0)$ & $0(0.0)$ & $8.8(0.4$ to 185$)$ \\
& Right or left & $3(1.4)$ & $0(0.0)$ & $12.4(0.6$ to 242$)$ \\
& Right or left & $24(11.5)$ & $9(2.5)$ & $5.1(2.3$ to 11.3$)$ \\
\hline
\end{tabular}

ॠWhen the number of subjects with epicondylitis was zero, the estimator for OR was calculated by adding 0.5 .

†Lateral or medial epicondylitis.

0.5 to 6.1 ), although tenderness to palpation was distinctively more prevalent in the right arm than in the left (cooks OR 2.5, 95\% CI 1.4 to 4.5 ; controls OR $2.2,95 \%$ CI 1.1 to 4.5 ). A difference between right and left arms was common in both right or left handed workers among both cooks and controls. No epicondylitis was found among left handed workers but numbers were few (13 cooks $(6.2 \%)$ and 13 controls $(3.6 \%))$. The difference in findings between the right and left arms was not significant for medial epicondyles.

ASSOCIATION OF RISK FACTORS AND OUTCOME VARIABLES IN COOKS

For self estimated job stressors and workload, most of the cooks complained of problems related to mechanical workload including static work posture and frequent repetitive work involving shoulders, arms, hands, or fingers (table 6 ). The cooks also often complained of too much work, too many different tasks, and much pressure on time. The ORs for those job stressors and workload were $>1.5$ with the lower limit of $95 \%$ CI $>1.0$ when the complaints of cooks were compared with those of controls (table 6).

Workers with and without epicondylitis among cooks and controls did not have different combined values for age, body length, body weight, BMI, and the duration of employment. Those with epicondylitis had lower grip strength $(23.2 \mathrm{~kg}$ in the right hand and $22.8 \mathrm{~kg}$ in the left on average) than those without the disorder (26.4 kg and $25.4 \mathrm{~kg}$, respectively). The differences between them were $3.2 \mathrm{~kg}$ (95\% CI 1.4 to 4.9 ) in the right and $2.6 \mathrm{~kg}$
(95\% CI 0.9 to 4.2 ) in the left. No worker with epicondylitis was found to habitually play tennis or other ball games. In the comparison between cooks with and without epicondylitis, differences in these variables were similar to those found in all the subjects combined. The number of meals prepared for lunch and the number of meals prepared per cook did not differ between the cooks with and without epicondylitis.

In logistic regression models for all the subjects combined, the job title of cook was found to have a strong association with epicondylitis (OR 5.4 in model 1 and OR 4.8 in model 2) after adjustment for potential confounders such as age, body length, and BMI (table 7). In model 2, the ORs of JS1 and JS2 were $>1.0$ (OR 1.4 and 1.3 respectively) with a lower limit of the $95 \%$ CI of 1.0 , whereas JS3 gave an OR of only 0.9 with a $95 \%$ CI of 0.6 to 1.2 . These results were similar but the OR of JS2 became slightly larger (OR $1.7,95 \%$ CI 1.2 to 2.6 ) when the job title variable was omitted from model 2 (model 3). In a logistic regression model for cooks, the number of meals showed no association with epicondylitis (table 8). Its OR did not change even when JS1, JS2, and JS3 were eliminated from the model (OR 1.0, $95 \%$ CI 0.8 to 1.2). However, a weak association was found between JS1 and epicondylitis (OR 1.4, 95\% CI 1.1 to 1.7 ). There was no association between the number of meals per cook and epicondylitis when the number of meals per cook replaced the total number of meals in the model (OR 1.2, 95\% CI 0.6 to 2.4). The ORs of potential confounders were similar to those shown in tables 7 and 8 before adding exposure variables - such as job title in model 1 for all subjects combined, and the number of meals in the model for cooks - into the models. However, log likelihood statistics significantly changed after inclusion of job title in model 1 for all subjects combined (LR 20.3, p<0.01). This was not the case in the model for cooks after inclusion of the number of meals (LR 0.1, NS). Some potential confounders including body weight and the duration of employment were not used because they had high correlations with other potential confounders (Spearman rank correlation coefficient for all subjects combined 0.88

Table 6 Proportion (\%) of workers with the self estimated job stressors and workload and OR (95\% CI) in nursery school cooks and controls

\begin{tabular}{lrrr}
\hline & $\begin{array}{l}\text { NS Cooks } \\
(n=209) n(\%)\end{array}$ & $\begin{array}{l}\text { Controls } \\
(n=366) n(\%)\end{array}$ & OR (95\% CI) \\
\hline Frequent lifting and handling of objects & $128(61.2)$ & $265(72.8)$ & $0.6(0.4$ to 0.9$)$ \\
Static work posture & $192(91.9)$ & $214(58.5)$ & $7.9(4.9$ to 12.8$)$ \\
Frequent repetitive work with shoulders, arms, hands, or fingers & $192(91.9)$ & $230(62.8)$ & $6.6(4.1$ to 10.8$)$ \\
Too much work & $149(71.3)$ & $197(53.8)$ & $2.1(1.5$ to 3.0$)$ \\
Too many different tasks & $145(69.4)$ & $198(54.1)$ & $1.9(1.3$ to 2.7$)$ \\
Too much responsibility & $82(39.2)$ & $188(51.5)$ & $0.6(0.4$ to 0.9$)$ \\
Much concentration required & $147(70.3)$ & $287(78.6)$ & $0.6(0.4$ to 0.9$)$ \\
Great time pressures & $169(80.9)$ & $236(64.5)$ & $2.3(1.5$ to 3.4$)$ \\
Shortage of staff & $107(51.2)$ & $211(57.7)$ & $0.8(0.5$ to 1.1$)$ \\
Difficult human relations at work & $110(52.6)$ & $228(62.5)$ & $0.7(0.5$ to 0.9$)$ \\
Inexperienced in handling tasks & $30(14.4)$ & $76(20.8)$ & $0.6(0.4$ to 1.0$)$ \\
Much unplanned work & $71(34.0)$ & $172(47.0)$ & $0.6(0.4$ to 0.8$)$ \\
Extra work due to poor physical condition of colleagues & $109(52.2)$ & $167(45.6)$ & $1.3(0.9$ to 1.8$)$ \\
Role ambiguity in the workplace & $49(23.4)$ & $102(27.9)$ & $0.8(0.5$ to 1.2$)$ \\
Difficulties in realising one's ideas & $82(39.2)$ & $186(50.8)$ & $0.6(0.4$ to 0.9$)$ \\
Lack of frank discussion about work problems & $84(40.2)$ & $144(39.5)$ & $1.0(0.7$ to 1.5$)$ \\
Difficulties in lowering workload at reduced working capacity & $155(74.2)$ & $233(63.7)$ & $1.6(1.1$ to 2.4$)$ \\
\hline
\end{tabular}


Table 7 Logistic regression of epicondylitis in all subjects, cooks and controls $(n=575)$

\begin{tabular}{lll}
\hline Model & Independent variables & OR ${ }^{\star}(95 \%$ CI $)$ \\
\hline 1 & Age & $1.1(0.5$ to 2.3$)$ \\
& Body length & $1.6(0.8$ to 3.3$)$ \\
& Body mass index & $1.0(0.9$ to 1.1$)$ \\
& Job title & $5.4(2.4$ to 11.9$)$ \\
& Age & $1.3(0.6$ to 2.9$)$ \\
& Body length & $1.5(0.7$ to 3.1$)$ \\
& Body mass index & $1.0(0.9$ to 1.1$)$ \\
& Job title & $4.8(2.1$ to 11.0$)$ \\
& JS1† & $1.2(1.0$ to 1.5$)$ \\
& JS2† & $1.5(1.0$ to 2.3$)$ \\
& JS3† & $0.9(0.6$ to 1.2$)$ \\
& Age & $1.5(0.7$ to 3.0$)$ \\
& Body length & $1.4(0.7$ to 2.9$)$ \\
Body mass index & $1.0(0.9$ to 1.1$)$ \\
& JS1 $\dagger$ & $1.2(1.0$ to 1.4$)$ \\
& JS2 $\dagger$ & $1.7(1.2$ to 2.6$)$ \\
& JS3† & $0.8(0.6$ to 1.1$)$
\end{tabular}

$\star$ OR was calculated by postulating the differences of 10 years for age and $10 \mathrm{~cm}$ for body length.

†JS1 was used as a suspected job stressor or workload score for psychosocial stressors, JS2 was that for mechanic workload, and JS3 was that for the amount of work, which were based on the results of factor analysis on self estimated job stressors and workload.

Table 8 Logistic regression of epicondylitis in nursery school cooks $(n=209)$

\begin{tabular}{ll}
\hline Independent variables & $O R^{\star}(95 \%$ CI) \\
\hline Age & $1.3(0.5$ to 3.6$)$ \\
Body length & $1.1(0.5$ to 2.6$)$ \\
Body mass index & $1.0(0.9$ to 1.2$)$ \\
No. of meals & $1.0(0.8$ to 1.3$)$ \\
JS1 $\dagger$ & $1.4(1.1$ to 1.7$)$ \\
JS2 $\dagger$ & $1.3(0.8$ to 2.2$)$ \\
JS3 $\dagger$ & $1.0(0.6$ to 1.5$)$ \\
\hline
\end{tabular}

*OR was calculated by postulating the differences of 10 years for age, $10 \mathrm{~cm}$ for body length, and 10 meals for the number of meals.

†JS1 was used as a suspected job stressor or workload score for psychosocial stressors, JS2 was that for mechanic workload, and JS 3 was that for the amount of work, which were based on the results of factor analysis on self estimated job stressors and workload.

between body weight and BMI, and 0.57 between age and the duration of employment). The number of meals was also highly correlated with job title so it was eliminated from models for all subjects combined (Spearman rank correlation coefficient for all subjects combined 0.96). The habit of playing tennis or other ball games was not analysed. No statistical interactions were found between exposure and possible confounding variables in likelihood ratio $\chi^{2}$ tests in the models. Similar results in logistic regression models were also replicated when lateral epicondylitis was used as a dependent variable instead of epicondylitis.

\section{Discussion}

PREVALENCE

There was a higher prevalence of epicondylitis in the nursery school cooks than in the controls. This result accorded with reports on those who cooked school lunches. ${ }^{16}{ }^{20}$ Huang et al found a higher prevalence of clinical signs of epicondylitis among cooks in a workplace with a large mechanical workload than among those in another workplace with a less stressful workload, although the difference was not significant due to the few subjects. ${ }^{6}$ Takeuchi et al also reported that $8.6 \%$ of cooks had continuous right arm pain in the month before the study in contrast with $3.5 \%$ in the clerical workers and handywomen controls. ${ }^{1}$ In the study by Oze, about $13 \%$ to $20 \%$ of cooks for school lunch service also had right arm pain almost every day during the month before the survey. ${ }^{20}$

In some studies, the criteria for epicondylitis were tenderness to palpation of the epicondyle and epicondylar pain provoked by resisted extension or flexion of the wrist and fingers with the elbow extended. ${ }^{13}{ }^{14-23}$ In this study, we used the criteria from those studies for epicondylitis in the examination. Ranney indicated that searching for tenderness is only the first step in reaching a specific diagnosis and that a more definitive test involves resisted movements, and we included these. ${ }^{24}$ The prevalence of lateral epicondylitis among workers with strenuous jobs was far lower in some other studies than in ours. ${ }^{21} 23$ Dimberg, however, found a similar prevalence to our study of $11 \%$ among white collar workers, ${ }^{13}$ and the prevalence increased to $13.9 \%$ when the age of subjects was restricted to 40 or older. Age must be controlled for when comparing studies as there are reports that epicondylitis is more prevalent between the ages of about 40 and 50 years. ${ }^{25-27}$ However, it is not feasible to calculate the prevalence according to the age strata given in most of the studies because the full raw data were not usually reported. The prevalence of medial epicondylitis in our study was close to that in other studies $(3.3 \%$ by Luopajärvi et al and $0.2 \%$ by Viikari-Juntura et al). ${ }^{2123}$

Some studies of epicondylitis adopted slightly different diagnostic criteria from ours; for example they included tests of hand grip strength or excluded the resisted wrist extension and flexion tests. ${ }^{28}{ }^{29}$ Lateral and medial epicondylitis were not distinguished in some studies. ${ }^{28}{ }^{29}$ These differences in diagnostic criteria and the site of the lesion interfere with the comparison among studies. Recently, Ranney et al proposed broader diagnostic criteria including a pain distal to the epicondyle but in the proximal half of the forearm, which was based on their idea that the tenderness of the epicondyle is a proximal extension of the primary problems in the forearm muscles due to repetitive movement. ${ }^{24}{ }^{30}$ They used the term "epicondylitis and/or tendinitis" for the problem meeting the criteria and found a prevalence of $15 \%$ laterally and $7 \%$ medially in female workers with highly repetitive jobs. However, they also reported that epicondylitis based on an isolated finding was found in only $3 \%$ of workers laterally and around $2 \%$ medially. Thus the prevalence of lateral epicondylitis in cooks seemed to be compatible with that in the highest group in other studies. However, when the age of the subjects was considered, there was no definite evidence that the prevalence in cooks was especially high. To attain good scientific comparability between studies, not only the use of identical diagnostic criteria but also adjustment for demographic factors including age and sex was necessary as well as the indication of the site of the lesion - in the right or left elbows - and lateral or medial epicondyles. 
In most studies, the difference in prevalence was not significant between subjects with strenuous occupations and the workers in the control groups, although RRs exceeded 1.0. ${ }^{31} \mathrm{It}$ is noteworthy that significantly higher prevalence of epicondylitis was found in the nursery school cooks than in the controls of our study. The cooks also had a higher prevalence of self estimated job stressors and workload suggesting mechanical stress such as static work posture and frequent repetitive work involving shoulders, arms, hands, or fingers. Moreover, the JS2 suggested that mechanical workload including repetitive work and static work postures tended to be associated with epicondylitis in logistic regression models. These results support the hypothesis that the prevalence of epicondylitis is higher in nursery school cooks than other workers with less strenuous tasks due to their frequent repetitive and forceful hand and arm tasks.

Significant differences in prevalence were also found between the lateral and medial sides and between the right and left elbows both in the cooks and in the controls in the present study. The dominance of the lateral side and the right elbow was concordant with other studies. ${ }^{23} 3032$ Dimberg reported epicondylitis in the dominant arm in $95 \%$ of the cases studied. ${ }^{13}$ Other researchers also noted that the working hand was more often affected..$^{263}$ In our study, however, positive findings were prevalent in the right arm, in both right and left handed subjects. One of the possible explanations for the susceptibility of the lateral epicondylar region might be the difference between wrist extensor and flexor forces. Werner et al found that larger extensor tendon forces were required than flexor forces in most of the wrist motions including flexion and extension when they studied tendon forces with a wrist joint motion simulator in cadavers. ${ }^{34}$ Moreover, movements thought to be of risk to elbow disorders were considered to be different in the lateral and medial epicondyles. ${ }^{15}$ A next step in the study of elbow problems should include an analysis of the workload that can assess the difference between the right and left elbows and between the lateral and medial side of epicondyles.

\section{RISK FACTORS}

In the logistic regression model, job title was included and the risk of epicondylitis for nursery school cooks was as much as five times that of a nurse or a handywoman. Several risk factors for epicondylitis in industry have been documented. ${ }^{13152635}$ Risky movements related to lateral epicondylitis included frequent rotary motions of the wrist, frequent lifting with the palm down, and repeated gripping activities, particularly if the elbow is extended and the wrist flexed. ${ }^{15}{ }^{35}$ Medial epicondylitis can be caused by forceful pronations of the forearm or forceful repeated flexion at the wrist. ${ }^{15}$ In the study by Dimberg, overexertion of the extensor muscles of the wrist due to gripping and twisting movements before the start of symptoms of the elbow was verified in $70 \%$ of the people with epicondylitis. ${ }^{13}$ Neither the frequency of the gripping nor the twisting movement related to wrist extensor and flexor muscles were considered in our study because of the difficulty of preparing a valid questionnaire for these variables. However, the prevalence of complaints about repetitive work involving shoulders, arms, hands, or fingers was found to be as high as $91.9 \%$ in cooks. The ORs for the variable JS2 was $1.3-1.7$ in the logistic regression models suggesting that mechanical stress like repetitive work and static load plays a part in epicondylitis. The lack of significant association for epicondylitis and JS2 within the cooks (table 8) could be explained by the fact that variance for JS2 in this group was low (most cooks had the same amount of static load and repeated work in their work tasks). From our on site inspection of workplaces, nursery school cooks often gripped devices and materials and twisted their wrist in cooking, washing, and cleaning. Thus it would be important and relevant to plan a field survey in the future on the relation of repetitive arm and hand motion to epicondylitis.

We did not find associations between demographic factors and epicondylitis. Only decrease in grip strengths was related to epicondylitis. This, however, could be a sign of elbow impairment and should be regarded as one of the clinical signs of epicondylitis and thus grip strength was not used as a independent variable (confounder) in the logistic regression models that analysed the association of work exposure and epicondylitis. ${ }^{28}$

The number of meals to be prepared for lunch and the number of meals to be prepared per cook were not associated with epicondylitis. These results are different from those in a study on cooks of school lunches which showed an association between the number of meals and prevalence of arm pain. ${ }^{36}$ One possible explanation would be the small variation in the number of meals (40-180/day) in our study on nursery school cooks, versus the far larger numbers (around 150-15000/day) in the study on cooks of school lunches. Another explanation might be the effects from factors unrelated to the number of meals - such as poor facilities in some workplaces.

Psychosocial factors were found to have small associations with epicondylitis, ORs 1.21.4. Even within the cooks the combined variable for psychosocial factors JS1 showed an association with epicondylitis (table 8). The usual number of nursery school cooks per worksite is only two. They have to cooperate to make meals and wash the dishes in a restricted work area within the limited time of the working hours. They need well established consensus on ways to deal with their individual and collective tasks by reducing differences of ideas through frank discussion. Although such good human relations are indispensable for their hectic tasks, it is often very difficult for the cooks to establish optimal relations. Bongers et al proposed a model of psychosocial factors directly influencing the mechanical load through changes in posture, movement, and exerted forces. ${ }^{37}$ They also proposed an indirect influence of psychosocial factors by 
increasing muscle tonus and moderating the relation between mechanical load and musculoskeletal symptoms. Thus psychosocial factors might have a large influence on the musculoskeletal system of the cooks through direct and indirect pathways.

In summary, risk factors of epicondylitis are considered to be multifactorial, and include mechanical workload and psychosocial factors.

INTERNAL VALIDITY AND PRECISION

In this study, the cooks were compared with the controls, who included nurses, nursing assistants, and workers with similar care giving tasks. This comparison seems relevant because other studies have failed to find any risks of arm and elbow problems among nurses, nursing assistants, and other workers in related jobs. Engels et al studied whether nursing staff in nursing homes regularly had musculoskeletal complaints and found that elbow and forearm complaints were mentioned by only $3 \%$ of the workers, whereas $38 \%$ and $27 \%$ of them had back and neck complaints respectively. ${ }^{38}$ Ono et al reported that nursery school workers had lower risks of shoulder or arm diseases than the general population of all other employed women in Sweden. ${ }^{39}$ However, there have been some studies in Japan suggesting a risk for the arm region in nurses and nursery workers. ${ }^{40-42}$ Hisashige and Ohara found that nurses had a higher prevalence than clerical workers of arm and shoulder symptoms, including pain. ${ }^{41}$ The OR of epicondylitis, therefore, might have been relatively greater in cooks had they been compared with another control group - such as housewives.

As only one or two workers a year retired from the job of nursery school cook due to some disorder in our study, it is unlikely that the study was biased by the early retirement of employees. However, there is no information available on the job selection process when people vulnerable to hazardous exposure or with low physical capacity might avoid potentially stressful occupations. Moreover, the cooks with severe musculoskeletal symptoms could occasionally change their jobs from cook to handywoman after many years of work. Thus the effects of work on the elbows may be to some extent masked by selection bias. ${ }^{43}$

The classification of job title seems reliable, as was confirmed at the interview. However, there remains the possibility of differential misclassification as there is a possible overreporting of self estimated job stressors and workload in subjects with epicondylitis. This may result in exaggerated OR values for exposure. An assessment of the extent of this information bias is difficult, and it may be advisable to use better validated exposure variables in the future as a scientific basis for ergonomic epidemiology ${ }^{44}$ Misclassification of outcome is a possibility, as the examination took six days to deal with all subjects, and measurements by the same examiner might have varied during the period. However, the proportion of the subjects with diagnosed epicondylitis only varied from $4.6 \%$ to $9.5 \%$, and no systematic trend with the examination days was found. Thus error within the examiner was thought not to be large. There could be non-differential misclassification of the outcomes if the examiner have some systematic distortion in his method of examination. Even though the examiner was well trained, there was no chance for anyone else to check the method of measurement during the examination period. Subjects psychologically sensitive to pain provoked by the test, might be the cause of differential misclassification of the outcome if many cooks were aware of the musculoskeletal disorders of their colleagues. We have no information on this.

As many comparisons and statistical tests were carried out in the study, some might have resulted in significance by chance. There has been no totally satisfactory solution to this problem of multiple testing, and careful interpretation of statistical results is necessary in the study. ${ }^{18} 45$

\section{Conclusions}

Nursery school cooks had a higher prevalence and a higher risk for epicondylitis than the controls. The cooks also had a higher prevalence of self estimated job stressors and workload such as static work posture and frequent repetitive work involving shoulders, arms, hands, or fingers. In a logistic regression model of all subjects combined, job title of cook was found to have a strong association with epicondylitis after adjustment for age, body length, and BMI. These results support the hypothesis that nursery school cooks have a higher prevalence of epicondylitis than other workers who have less strenuous hand and arm tasks.

Associations were found between epicondylitis and suspected job stressor or workload scores for mechanical workload and psychosocial stressors based on factor analysis. In the model for cooks, the number of meals cooked altogether and meals cooked per cook had no association with epicondylitis. Thus, it was suggested that risk factors of epicondylitis would be multifactorial, and included mechanical workload and psychosocial factors.

In the discussion of the validity of comparison, selection, and information, many types of possible bias in the study were indicated, including underestimation of the outcomes from control occupations, selection bias in cooks, and misclassification of exposure and outcome.

\footnotetext{
1 Takeuchi Y, Tanaka T, Ohkawa H. On health disorders in workers for school lunch. Fapanese fournal of Industrial Health 1975;17:483-9. (In Japanese with English abstract, tables, and figures.)

2 Nagira T, Suzuki J, Oze Y, et al. Cervicobrachial and low-back disorders among school lunch workers and nursery-school teachers in comparison with cash-register operators. F Hum Ergol 1981;10:117-24.

3 Wærsted M, Westgaard RH. Repetitive strain injuries among service personnel on north sea oil platforms. In: Buckle P, ed. Musculoskeletal disorders at work. London: Taylor and Francis, 1987:153-8.

4 Nakamura R, Ono Y, Horii E, et al. The aetiological significance of work-load in the development of osteoarthritis of the distal interphalangeal joint f $\mathrm{Hand}$ Surg $[\mathrm{Br}]$ 1993;18: 540-2.

5 Oze Y. Studies on health hazards among cooks providing school lunch service. Report 2 . An analysis of factors associated with the development of health hazards. Fapanese fournal of Industrial Health 1984;26:425-37. (In Japanese with English abstract, tables, and figures.)
} 
6 Huang J, Ono Y, Shibata E, et al. Occupational musculoskeletal disorders in lunch centre workers. Ergonomics 1988;31:65-75.

7 Pekkarinen A, Anttonen H. The effect of working height on the loading of the muscular and skeletal systems in the kitchens of the workplace canteens. Applied Ergonomics 1988;19:306-8

8 Shibata E, Ono Y, Huang J, et al. Ergonomics problems among kitchen workers in nurseries. In: Kumashiro $M$ Megaw ED, eds. Towards human work: solutions to problems in occupational health and safety. London: Taylor and Francis, 1991:263-8.

9 Ono Y, Shibata E. Actual conditions of cooking work. Rodo no Kagaku (Science of Labour) 1993;48:196-200. (In Japanese.)

10 Winkel J, Mathiassen SE. Assessment of physical work load in epidemiologic studies: concepts, issues, and operational in epidemiologic studies: concepts, issues, and

11 Kilbom A. Repetitive work of the upper extremity: part II the scientific basis (knowledge base) for the guide. the scientific basis (knowledge base) for the guide. 86.

12 Silverstein BA, Fine LJ, Armstrong TJ. Hand wrist cumulative trauma disorders in industry. $\mathrm{Br} F$ Ind Med 1986;43: 779-84.

13 Dimberg L. The prevalence and causation of tennis elbow (lateral humeral epicondylitis) in a population of workers in an engineering industry. Ergonomics 1987;30:573-80.

14 Kurppa K, Viikari-Juntura E, Kuosma E, et al. Incidence of tenosynovitis or peritendinitis and epicondylitis in a meatprocessing factory. Scand $\mathcal{F}$ Work Environ Health 1991;17: 32-7.

15 Parker KG, Imbus HR. Cumulative trauma disorders. Boca Raton: Lewis, 1992.

16 Checkoway H, Pearce N, Crawford-Brown DJ. Research methods in occupational epidemiology. Oxford: Oxford University Press, 1989.

17 Sall JP, Stanish WM. The FREQ procedure. In: $S A S / S T A T$ user's guide version 6, 4 ed. Cary, NC: SAS Institute, 1989;1: user's guide 89.

18 Kleinbaum DG. Logistic regression. New York: SpringerVerlag, 1994

19 SAS Institute. SAS/STAT user's guide version 6, 4 ed. Cary, NC: SAS Institute, 1989;1:2.

20 Oze Y. Studies on health hazards among cooks providing school lunch service. Report 1 . The influence of working conditions in central and school kitchens on the prevalence of health hazards. Fapanese Fournal of Industrial Health 1984;26:414-424. (In Japanese with English abstract, tables, and figures.)

21 Luopajärvi T, Kuorinka I, Virolainen M, et al. Prevalence of tenosynovitis and other injuries of the upper extremities in repetitive work. Scand f Work Environ Health 1979;5:4855.

22 Waris P, Kuorinka I, Kurppa K, et al. Epidemiologic screening of occupational neck and upper limb disorders. Scand $\mathcal{F}$ Work Environ Health 1979;5:25-38.

23 Viikari-Juntura E, Kurppa K, Kuosma E, et al. Prevalence of epicondylitis and elbow pain in the meat-processing indus-
try. Scand 7 Work Environ Health 1991;17:38-45.

24 Ranney D. Work-related chronic injuries of the forearm and hand: their specific diagnosis and management. Ergonomics 1993;36:871-80.

25 Allander E. Prevalence, incidence and remission rates of some common rheumatic diseases and syndromes. Scand $\mathcal{F}$ Rheumatol 1974;3:145-53.
26 Goldie I. Epicondylitis lateralis humeri: a pathogenetical study. Acta Chir Scand 1964;339(suppl):1-119.

27 Kurppa K, Waris P, Rokkanen P. Tennis elbow: lateral elbow pain syndrome. Scand $\mathcal{F}$ Work Environ Health 1979;5:15-8.

28 Roto P, Kivi P. Prevalence of epicondylitis and tenosynovitis among meatcutters. Scand $\mathcal{F}$ Work Environ Health 1984;10: 203-5.

29 McCormack RR, Inman RD, Wells A, et al. Prevalence of tendinitis and related disorders of the upper extremity in a manufacturing workforce. 7 Rheumatol 1990;17:958-64.

30 Ranney D, Wells R, Moore A. Upper limb musculoskeletal disorders in highly repetitive industries: precise anatomical physical findings. Ergonomics 1995;38:1408-25.

31 Hagberg M, Silverstein B, Wells R, et al. Evidence of work relatedness for selected musculoskeletal disorders of the neck and limbs. In: Kuorinka I, Forcier L, eds. Work related musculoskeletal disorders (WMSDs): a reference book for prevention. London: Taylor and Francis, 1995:17-137.

32 Lambrecht W. Wesen und Behandlung der Epicondylitis humeri. Chirurgie 1948;19:55-8.

33 Bosworth DM. The role of the orbicular ligament in tennis elbow. F Bone foint Surg 1955;37:527-33.

34 Werner FW, Palmer AK, Somerset JH, et al. Wrist joint motion simulator. f Orthop Res 1996;14:639-46.

35 Simmons BP, Wyman ET. Occupational injuries of the elbow. In: Millender LH, Louis DS, Simmons BP, eds. Occupational disorders of the upper extremity. New York: Churchill Livingstone, 1992:155-62.

36 Ono Y, Hosokawa M, Maeda K, et al. Occupational cervicobrachial disorders (OCD) and associated back pain in Japan. In: Osterholz U, Karmaus W, Hullmann B, et al, eds. Work-related musculo-skeletal disorders. Bonn: Wirtschaftsverlag NW, 1987:279-305.

37 Bongers PM, de Winter CR, Kompier MA, et al. Psychosocial factors at work and musculoskeletal disease. Scand $\mathcal{f}$ Work Environ Health 1993;19:297-312.

38 Engels JA, van der Gulden JWJ, Senden TF, et al. Physical work load and its assessment among the nursing staff in nursing homes. f Occup Med 1994;36:338-45.

39 Ono $\mathrm{Y}$, Lageström $M$, Hagberg $M$, et al. Reports of work related musculoskeletal injury among home care service workers compared with nursery school workers and the general population of employed women in Sweden. Occup Environ Med 1995;52:686-93.

40 Kurumatani N, Iki M, Katagi K. A study on occupational cervicobrachial disorder (OCD) of nursery school teachers based on subjective symptoms related to OCD fapanese fournal of Industrial Health 1984;26:389-96. (In Japanese with English abstract, tables, and figures.)

41 Hisashige A, Ohara H. Analysis of fatigue and health conditions among hospital nurses. Fournal of the Science of Labour 1985;61:517-28. (In Japanese with English abstract.)

42 Ono Y, Shimaoka M, Hiruta S, et al. A comparative study of the perceived job stress among nursery school teachers based on the age of children in their care. Nagoya fournal of Health, Physical Fitness, and Sports 1991;14:83-90. (In Japanese with English abstract, tables, and figures.)

43 Hernberg S. Introduction to occupational epidemiology. Chelsea: Lewis, 1992.

44 Hagberg M. Exposure variables in ergonomic epidemiology. Am F Ind Med 1992;21:91-100.

45 Altman DG. Practical statistics for medical research. London: Chapman and Hall, 1991.

\section{Rejected manuscripts}

From February 1994, authors whose submitted articles are rejected will be advised of the decision and one copy of the article, together with any reviewer's comments, will be returned to them. The fournal will destroy remaining copies of the article but correspondence and reviewers' comments will be kept. 